\title{
Natural hydroxyapatite as a bone graft extender for posterolateral spine arthrodesis
}

\author{
Christophe Garin $^{1} \cdot$ Séverine Boutrand ${ }^{1}$
}

Received: 10 February 2016 / Accepted: 15 February 2016 / Published online: 10 March 2016

(C) The Author(s) 2016. This article is published with open access at Springerlink.com

\begin{abstract}
Purpose The aim of this retrospective analysis of spinal fusion, was to document the clinical, functional, and radiological outcomes with a local bone graft plus the highly osteoconductive hydroxyapatite, bio-derived Orthoss ${ }^{\circledR}$, with or without bone marrow aspirate.

Methods Forty seven patients submitted to spinal posterolateral fusion were operated for four major indications: scoliosis in young patients (11), degenerative spine (18), lumbosacral transitional anomalies in young adults (14), and spine trauma (four). Sixteen patients had more than four levels fused. In addition to spinal decompression and instrumented fusion, autologous bone grafts from the excised lamina were augmented with Orthoss ${ }^{\circledR}$ granules in a 1:1 ratio. In addition iliac crest bone marrow aspirate was used in $70 \%$ of the patients. The results were assessed clinically in terms of pain, and return to school or professional activities were checked at three, six, and 12 months following surgery with a mean follow-up of 20 months. In scoliotic patients, correction of the major angle was evaluated from one to four years after surgery.

Results Pain persistence was reported only in four cases, after three months after surgery. A functional recovery was noted in almost all patients groups within these three months. Progressive bone formation with evidence of bone fusion masses were already observed at six months. No fusion failure was observed.

Conclusions Local bone enhanced by an osteoconductive long-term stable scaffold, used with and without bone marrow
\end{abstract}

Christophe Garin

garin.ch@club-internet.fr

1 Capio Polyclinique du Beaujolais, 120 ancienne route de Beaujeu, 69653 Villefranche sur Saône Cedex, France aspirate, led to successful fusion in all patients by six months while functional recovery was reported already within three to six months.

Keywords Bone graft substitute $\cdot$ Bone marrow aspirate . Lumbar degenerative spine $\cdot$ Orthoss $^{\circledR} \cdot$ Scoliosis $\cdot$ Spinal posterolateral fusion

\section{Introduction}

Spinal arthrodesis is performed in several indications to relieve pain and correct deformities. In lumbar spondylolisthesis, the spine is stabilized to reduce pain and disability in patients with chronic back pain. In young scoliotic patients, fusion is proposed after conservative treatments to ensure the realignment and stabilization of scoliotic deformities. After trauma, vertebral body stabilization often utilizes instrumented fusion. Commonly, the fusion process is stimulated and sustained by local delivery of biological ingredients. Typically, bone grafts, bone debris, bone graft substitutes, and/or biological adjuncts, help achieve bone fusion mass formation adjacent to the vertebral bodies, and instrumented fusion together with bone masses are known to provide durable stabilization. The induction of such heterotopic osteosynthesis requires nevertheless a complex balance of biological factors and operative technique to achieve successful fusion [1].

Surgical techniques for spinal arthrodesis have evolved from purely non instrumented procedures to wiring techniques, polyaxial screws, locked plating, and rod technology [2]. Even more, several spinal fusion procedures can be combined to ensure an initial stability of deformed vertebral structures. To aid these procedures, commercially available bone grafts, bone graft extenders, and osteobiologics have been developed with the goal of decreasing the surgical 
morbidity associated with harvest of autologous iliac crest bone grafts (ICBG). Although ICBG still represents the gold standard, postoperative pain affecting $16-40 \%$ of patients and major complications such as vascular injury, nerve injury, fracture or hernias are still reported in up to $8.6 \%$ of cases [3]. To avoid the grafting morbidity and potential complications, percutaneous aspiration of bone marrow stem cells from the iliac crest is a viable alternative. Specifically, a tenfold reduction in complications has been reported with the use of this methodology over classical iliac crest bone graft harvesting in reconstructive surgery by Hernigou et al. [4]. Accordingly, bone marrow aspirate was used in our patients to circumvent the need for an iliac crest bone graft, whenever possible.

The present retrospective analysis reports outcomes from the daily practice of single and multilevel spinal fusions. We used the unique combination of local bone, with or without bone marrow graft aspirate, or in a limited number of cases ICBG, to provide osteogenic progenitors. In addition, a structural osteoconductive scaffold was used as a bone graft extender to support long term stability of newly formed bone. The selection of the osteoconductive agent was based on its physical architecture, chemical nature, and its stability over time. Since the rate of resorption is a critical factor when considering bone grafts as adjuncts to spine fusion, rapid resorbing calcium sulfate, or even $\beta$-TCP, were not considered in our practice. Moreover, synthetic sintered hydroxyl-apatite was not used due to its limited interconnected porosity. The issue of early or rapid graft dissolution before sufficient osteoconduction led us to consider the use of a highly osteoconductive and interconnected porous bone substitute of hydroxyapatite nature.

Orthoss ${ }^{\circledR}$ (Geistlich Pharma AG, Wolhusen, Switzerland) is a bovine-derived bone substitute, which has the structure of the native trabecular bone, with unique interconnected porosity. It is a natural hydroxyapatite, with no residual protein or other organic material, having a high spontaneous permeability to cells and fluids, is rapidly surrounded by new bone without foreign body reaction or encapsulation. Due to its nature, it resorbs very slowly with time (over years) making it valuable for spine surgery.

This material was able to enhance rapid and complete bone ingrowth while remaining as a stable scaffold to maintain the long term volume stability of the heterotopic bony fusion.

The present report on spinal fusion in various indications, includes complex fusion procedures involving more than two levels. We used the osteoconductive Orthoss ${ }^{\circledR}$ hydroxyapatite together with local bone debris from the decortication of the pedicles and vertebra, and additional bone marrow stem cells from the bone marrow aspirate to support fusion. Osteoinductive agents were not used due to safety concerns particularly in a young patient population, and to the variability of the BMP content of the different DBM preparations [2].

\section{Material and methods}

Forty seven consecutive patients submitted to spinal posterolateral fusion in the period 2010-2011 were operated for four major indications: scoliosis in young patients $(n=11)$, degenerative spine $(n=18)$, lumbosacral transitional anomalies in young adults $(n=14)$, and spine trauma $(n=4)$. The respective indications include evolutive scoliosis despite physiotherapy and continuous orthotic treatment, and persistent low back pain with or without neurological compromise that failed to respond to at least 6 months of conservative treatment for the degenerative and transitional anomalies.

Demographic data concerning the four patient groups, the duration of follow-up, and the number of fusion levels are summarized in Table 1. A total of 16 patients had more than four levels fused. As expected, the higher number of fusion levels was observed in scoliotic patients, with more than four levels involved in ten of these patients. In the other indications, the majority of patients had two disc fusion levels. Two patients were lost to follow-up in the immediate postoperative period, so the report concerns 45 patients with a mean follow-up of 20 months (up to 48 months).

In patients with degenerative spine, or lumbosacral anomalies, posterior decompression was achieved through laminectomies and facetectomies at each concerned level. Instrumented fusion was realized using pedicle screws, rods, and plates. Rods were angulated as necessary. Autologous bone grafts from the excised lamina were used bilaterally, augmented with Orthoss ${ }^{\circledR}$ granules of 2-4 mm (amount of $7 \mathrm{~g}$ mixed 1:1 with autologous local bone).

Patients with scoliosis were all treated with posterior correction using Tenor instrumentation after opening the facets, decortication of the laminae, transverse, and spinous process. Local bone chips from the decortications, augmented with Orthoss ${ }^{\circledR}$ granules, were placed on the opened facets and decorticated surfaces.

Spine trauma was treated with posterior reduction using Tenor osteosynthesis screws and rods. The instrumented fusion was completed in all cases with bone fusion using local bone chips, mixed with Orthoss ${ }^{\circledR}$ granules.

Orthoss ${ }^{\circledR}$ is a commercially available bone substitute of bovine origin, obtained by a validated processing method that enables organic components to be removed, while maintaining the porous trabecular structure of the native bone (Fig. 1). The granules are rapidly invaded by the surrounding bone cells and their hydroxyapatite nature is associated with a very low resorption rate [5].

In addition to local bone available from decortication and Orthoss ${ }^{\circledR}$ granules, iliac crest bone marrow aspirate collected through percutaneous aspiration was used in $13 / 18$ patients treated for degenerative spine, ten/14 patients treated for lumbosacral transitional anomalies, in three/four patients with spine trauma, and in seven/11 patients treated for scoliosis. In total, 33 
Table 1 Cumulative patient data. Ø mean

\begin{tabular}{|c|c|c|c|c|}
\hline \multirow[b]{2}{*}{$\begin{array}{l}\text { Indication and patient } \\
\text { number (n) }\end{array}$} & \multicolumn{4}{|l|}{47 spine patients } \\
\hline & Trauma (4) & Degenerative spine (18) & $\begin{array}{l}\text { Lumbosacral transitional } \\
\text { anomalies (14) }\end{array}$ & $\begin{array}{l}\text { Scoliosis in young } \\
\text { patients (11) }\end{array}$ \\
\hline Mean age (years), male, female & $64(53-77), 1 \mathrm{~m}, 3 \mathrm{f}$ & $62(50-77), 4 \mathrm{~m}, 14 \mathrm{f}$ & $36(15-48), 4 \mathrm{~m}, 10 \mathrm{f}$ & $18(13-35), 1 \mathrm{~m}, 10 \mathrm{f}$ \\
\hline \multirow[t]{3}{*}{ Levels involved, (n) } & $1-2(0)$ & $1-2(12)$ & $1-2(11)$ & $1-2(1)$ \\
\hline & $3(2)$ & $3(3)$ & $2-3(2)$ & $3(0)$ \\
\hline & $\geq 4(2)$ & $\geq 4(3)$ & $\geq 4(1)$ & $\geq 4(10)$ \\
\hline \multirow[t]{5}{*}{ Follow-up, (n) $(\varnothing=20 \mathrm{~m}(4-48))$} & 4-6 m (3) & 4-6 m (4) & 4-6 m (2) & 4-6 m (2) \\
\hline & $1 \mathrm{y}(1)$ & $1 \mathrm{y}(4)$ & $1 \mathrm{y}(4)$ & $1 \mathrm{y}(4)$ \\
\hline & $2 \mathrm{y}(0)$ & $2 \mathrm{y}(4)$ & $2 \mathrm{y}(5)$ & $2 y(4)$ \\
\hline & $\geq 3 y(0)$ & $\geq 3 y(6)$ & $\geq 3 y(2)$ & $\geq 3 y(0)$ \\
\hline & $\varnothing=7.5 \mathrm{~m}(4-12)$ & $\varnothing=22 \mathrm{~m}(4-48)$ & $\varnothing=13 \mathrm{~m}(4-36)$ & $\varnothing=17 \mathrm{~m}(5-30)$ \\
\hline Lost to follow-up & 0 & 0 & 1 & 1 \\
\hline Revision surgery & 0 & 1 & 1 & 0 \\
\hline Adverse event (AE) & 0 & 2 & 1 & 0 \\
\hline
\end{tabular}

among 47 patients $(70 \%)$ were treated with bone marrow aspirate. Iliac crest bone grafts mixed with local bone and with Orthoss ${ }^{\circledR}$ granules were used only in two patients with transitional anomalies, in whom the iliac crest was exposed during the procedure. Local bone and Orthoss ${ }^{\circledR}$, without iliac crest graft or iliac bone marrow aspirate was used in five/18 degenerative spine, one/four trauma patients, four/11 scoliotic patients, and two/14 in patients with transitional anomalies. The decision to add bone marrow aspirate or not was based on the amount and quality of local bone available.

Posterolateral fusion was associated with interbody fusion using cages in eight patients (four in the degenerative spine and four in the young adult spondylolisthesis patients).

External immobilization by orthosis was prescribed after surgery in all patient groups for the duration of one to four months. The patients were encouraged to stand up and walk by the fifth postoperative day.

Outcomes were assessed clinically in terms of general conditions, return to school or professional activities at three, six, and

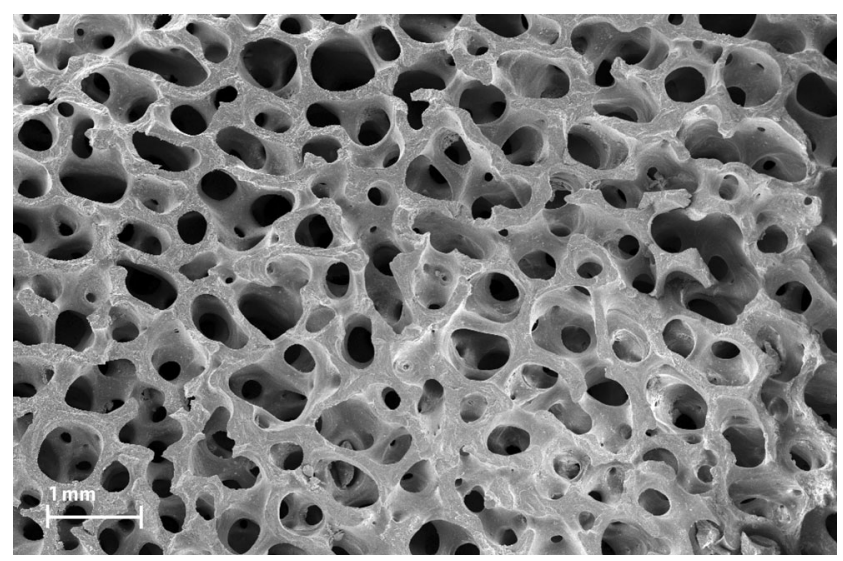

Fig. 1 Scanning electron microcopy of Orthoss ${ }^{\circledR}$ bone graft substitute
12 months following surgery. Pain in the spine or legs was graded by the surgeon at each post-operative visit. Radiologic assessments were performed on anteroposterior and lateral radiographs with the patient in neutral standing position. X-rays were taken before surgery, during the first week after surgery and at three, six, and 12 months. In scoliotic patients, the parameters measured were the Cobb angles of the curves on the frontal plane, thoracic kyphosis, and lumbar lordosis. Correction of the major angle (with $100 \%$ being the preoperative level), was evaluated at one and four to six months, one year, two years, and $\geq$ three years, and at the final follow-up. Success of the vertebral fusion was assessed by the clinical outcomes of reduction/absence of pain and function recovery for degenerative or transitional anomalies, as well as maintenance of the correction in scoliotic patients, and radiologic assessment for the fusion with no need for secondary surgery on the operated levels. Complications were classified as wound complications (infection, hemorrhage, and wound dehiscence), procedurerelated complications (nerve palsy/injury, need for subsequent procedure and bone fracture, implant failure, implant fracture) and non-union/delayed union in a separate group.

\section{Results}

Overall pain at the fusion site, and functional recovery (sport and/or professional activities) were evaluated according to the clinical reports of each patient. These parameters are summarized in Fig. 2a and b. Pain was reported after three months following surgery only in four cases. Except in four cases, functional recovery was noted in all patients groups within three to six months after surgery. 
a

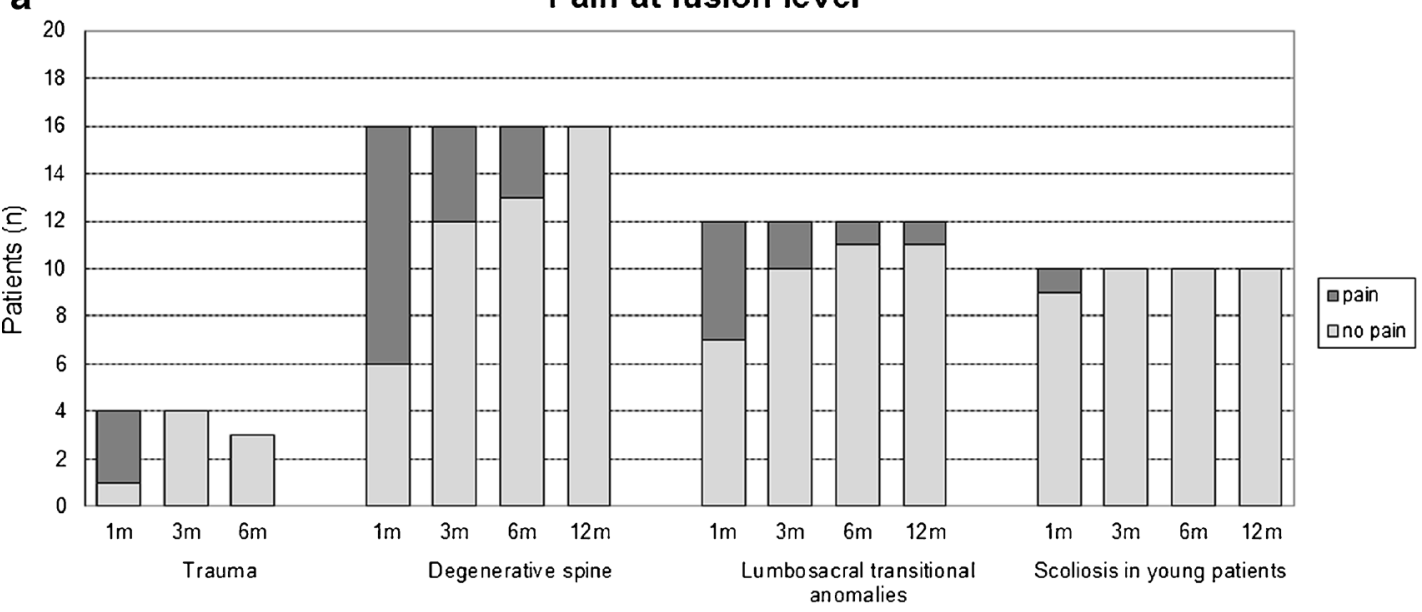

b

Functional recovery

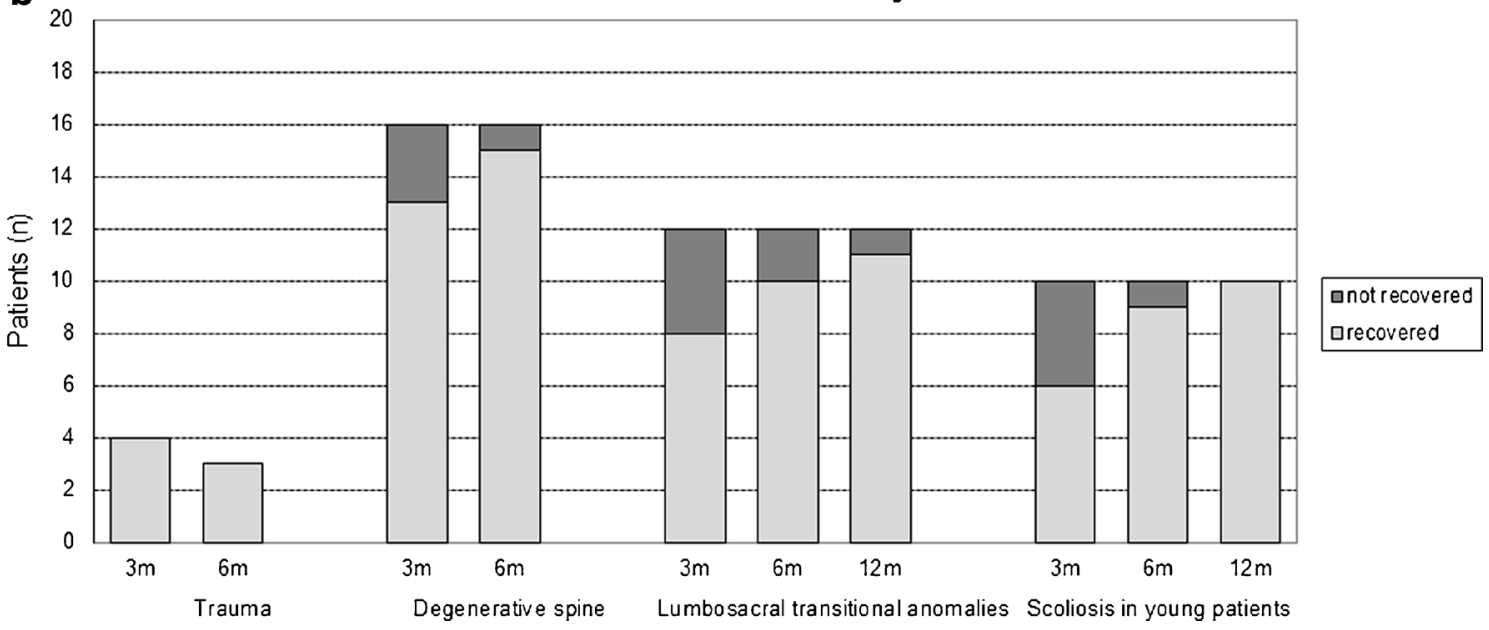

Fig. 2 a Evolution of the pain relief over time measured as pain at the fusion level in the four intervention groups. b Evolution of the functional recovery (sport and/or professional activities) over time in the four intervention groups

In the scoliosis group, ten patients could be followed regularly (one patient went to another hospital for personal convenience). Correction of the major angle at the final follow-up assessment was of $58 \% \pm 17.9 \%$ as compared to preoperative values. Post-operative radiographs showed progressive bone formation with evidence of bone fusion masses already observed at six months. No fusion failure was observed. No infection was reported in this patient group.

No neurologic or intra-operative/post-operative systemic complications were observed. Acute post-operative infection was reported in two patients, one being associated with early screw displacement. Reinstrumentation in a revision surgery was performed in two cases, after six weeks and ten months of the initial surgeries, respectively. Each adverse event is detailed below:

Infectious process starting at one month was treated with Pyostacin, but fistulas exposing the osteosynthetic material were observed at nine months in a degenerative spine surgery. Since the bone fusion was solid, the material was removed and not replaced.
Early displacement of the L4 screws after six weeks, in a patient with an indication of lumbosacral transitional anomaly with subsequent Staphylococcus Aureus contamination. Antibiotic therapy was initiated, the osteosynthetic material, was replaced including an additional fusion level (L3, local bone graft augmented with Orthoss $\left.{ }^{\circledR}\right)$. Stable fusion took place thereafter.

One patient in the degenerative lesion group had two additional surgeries. The first at ten months after the initial procedure (arthrodesis L4-S1 plus intersomatic cage L4-L5) for a radiating pain resistant to medication. The material on the right side was removed, L5-S1 foraminotomy and L4-S1 arthrodesis were performed. After two years, MRI confirmed the presence of additional discopathies superior to the arthrodesis at the L2L3 and L3-L4 levels without discal hernia. The material was removed and replaced by an extended osteosynthesis L3-S1 plus arthrectomy and posterolateral fusion. The follow-up of 3.5 months was uneventful. 
The radiological follow-up showed a progressive incorporation of the bone graft material into the fusion mass with time. Incorporation and integration was noted in almost all radiological reports at six months and thereafter. In all cases Orthoss ${ }^{\circledR}$ was used and contributed to the fusion mass. The radiodensity and the long term stability of the granules allow visualization at least two to three years though their radiopacity progressively decreases with time (Figs. 3, 4, and 5).

\section{Discussion}

Although the number of surgical options available to manage degenerative spondylolisthesis has increased in the last decade, decompression laminectomy with partial medial facetectomy and instrumented fusion remains the standard [6]. According to the Spine Patient Outcomes Research Trial (SPORT) subgroup analysis, no clear advantage of one fusion technique over any other has been observed [7]. However, the addition of interbody fusion should be considered in patients who are at high risk of non-union, local kyphosis, high grade slip, and/or symptomatic instability with sagitally oriented facet joints [6]. In the present study, the eight patients who benefited from additional interbody fusion in the degenerative spine group $(n=4)$ and in the transitional anomalies group $(n=4)$, had discal hernia recurrence, with evidence of disc degeneration. The rationale was to include an anterior column support, an indirect foraminal decompression, and a restoration of lordosis.

Variable fusion rates are reported in spine surgery depending on the surgical technique, the instrumentation used, single versus multiple fusion levels, and method of fusion detection [8]. The present clinical, functional, and radiological results dealing with multilevel treatments, are in agreement with published data in the corresponding indications, using various sources of bone grafts or bone substitutes. In this report, the combined use of local bone and an osteoconductive graft expander in all patients, was supplemented in $70 \%$ with bone marrow aspirate. This strategy allows:

At least a similar fusion rate as in previous series using only local bone with a solid fusion achieved in $94.9 \%$ for lumbar spondylolisthesis patients as reported by Kho and Chen [9]. A range of 65 to $95 \%$ of successful fusion rates based on plain radiographic imaging was reported [10]. The local available bone chips are of limited volume and insufficient for multilevel fusions. In addition, this local bone is largely cortical with a reduced number of progenitor cells as compared to spongious components. Because of this, there is a need for additional supply of both graft expander and cellular/ biological adjuncts in larger or high risk surgeries.

A similar fusion rate as with ICG: Dimar et al. [11] found a fusion rate of single-level instrumented posterolateral fusion from 89 to $83 \%$. The overall fusion rate achieved was reported at $75 \%$ for ICBG and $65 \%$ with local bone grafts [12]; however, when only multilevel fusions were performed, the fusion rates for ICBG and local bone were $66 \%$ and $20 \%$, respectively. Historical data report fusion rates with the use of iliac crest in PLF from 50 to $90 \%$ [10]. In addition, for scoliotic patients the mean correction of the deformity was in the range of published series using iliac crest graft, $57 \% \pm 14 \%$ for iliac crest graft group [13]. While patients in the age range 15-25 years tend to be in a time of life that favors good healing, i.e., the scoliotic group, it could be speculated that older patients with eventual comorbidities, osteoporosis, or smokers, might not achieve the same results with a purely osteoconductive bone graft substitute. In these conditions the concomitant use of bone marrow aspirate is to be
Fig. 3 Radiological follow-up of a 54 year old male patient treated for degenerative spine disease; a six days after surgery; $\mathbf{b}$ four months after surgery; c one year after surgery. Removal of the fixation nine months post-operative. Fusion achieved and bone substitute material still observed in the fusion mass
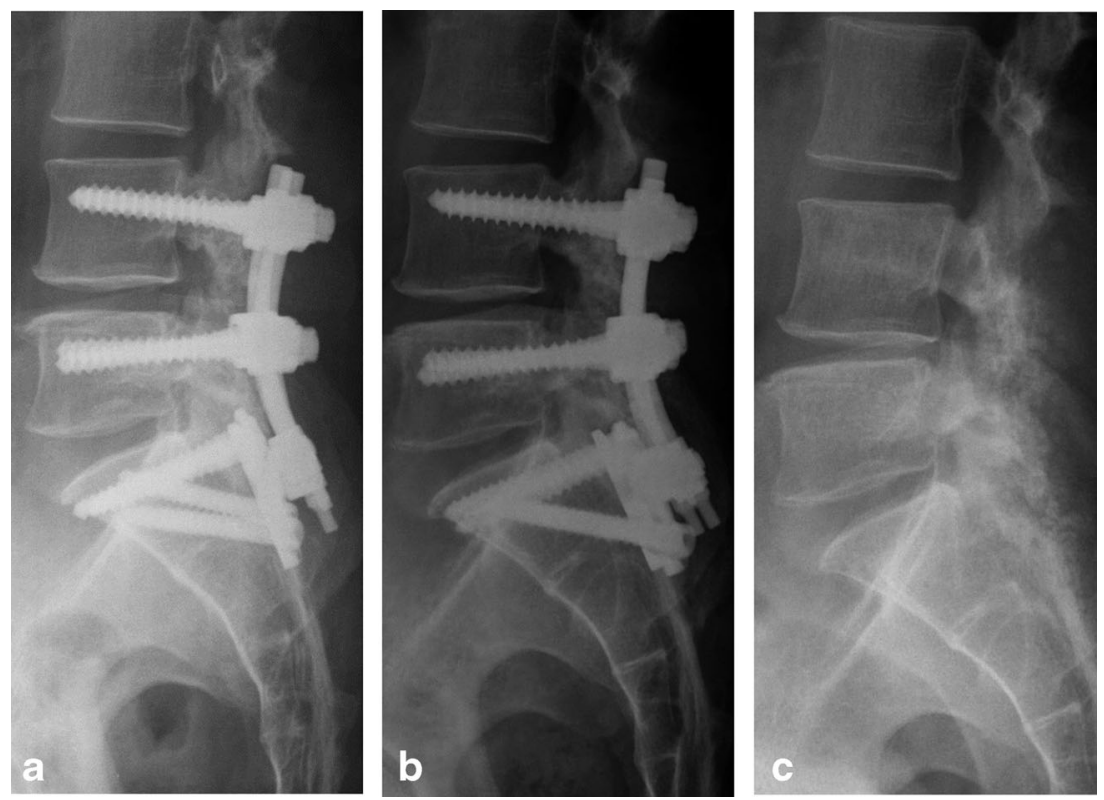
Fig. 4 Radiological follow-up of a 20 year old female treated for juvenile scoliosis T12/L4 (lateral a-d, anteroposterior $\mathbf{f - g}$ ). a six weeks after surgery; $\mathbf{b}$ five months after surgery the fusion mass is notable; $\mathbf{c}$ one year after surgery fusion achieved and bone substitute material still observed in the fusion mass; $\mathbf{d}$ two years after surgery bone substitute material still observed in the fusion mass; e 6 weeks after surgery; $f$ months after surgery the fusion mass is notable; $\mathbf{g} 2$ years after surgery bone substitute material still observed in the fusion mass
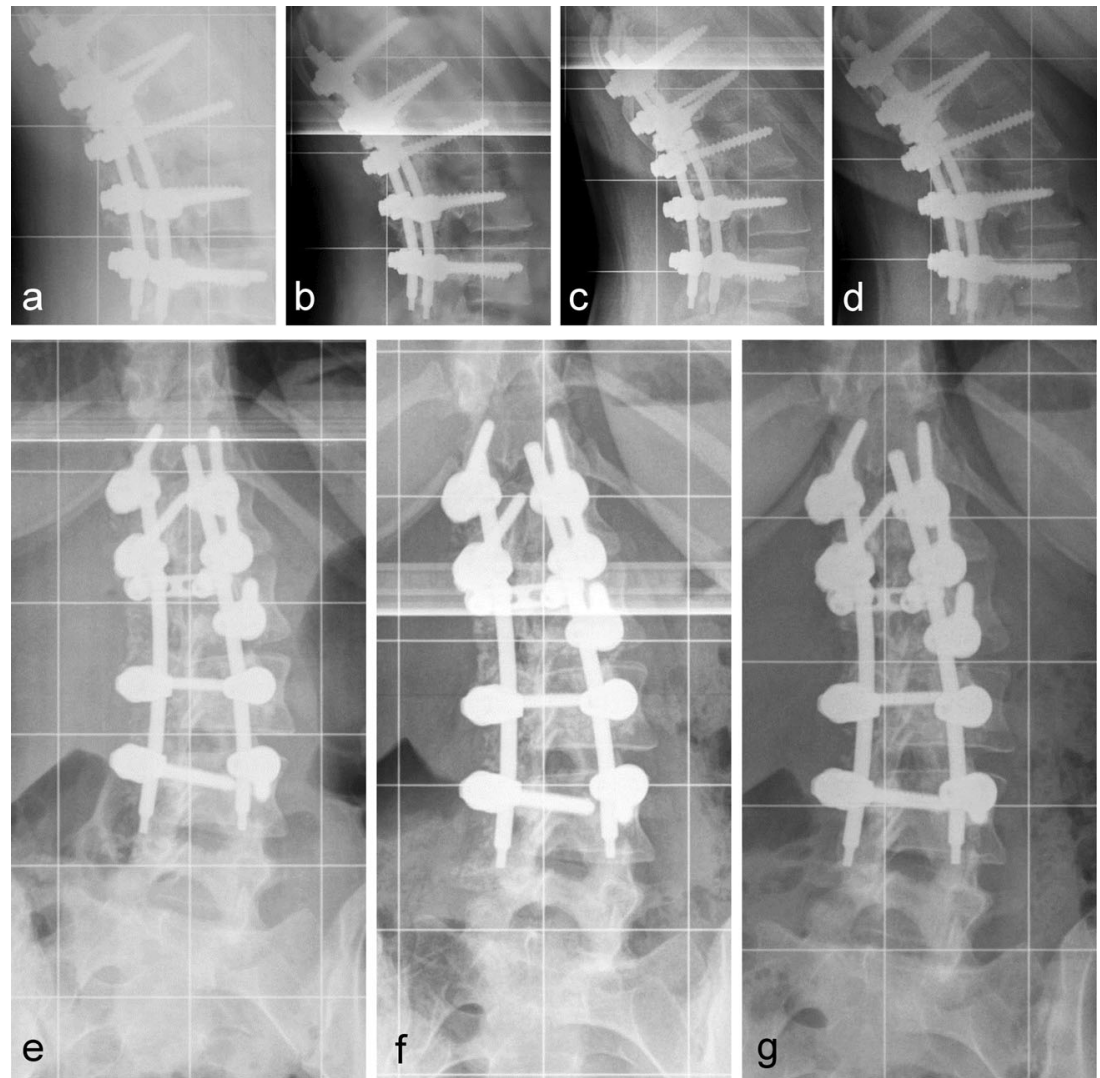

recommended. The use of bone marrow aspirate, which contains osteoinductive and osteogenic substances was suggested to compare favorably to iliac crest bone graft $[4,14]$. This is also confirmed by the present results in all indications studied.

The re-operation rate also compared favorably with a probability of repeat surgery of $6.3 \%$ at two years in the metaanalysis on the use of BMP in spinal fusions [15]. This number excluded device-related re-operations, which accounted in the meta-analysis for $25 \%$. Wound complications observed in our study are also in the range of reported values from $1.2 \%$ [16] to $6 \%$ [17]. Procedure reported complications were reported with an incidence of $5 \%$, implant related complications with an incidence of $1.1 \%$, non-union/delayed union at $0.1 \%$ [17], and overall major medical complications were reported in $3.1 \%$ of patients [16].

Concerning the selection of the bone graft extenders functioning as scaffolds on which fusion bone can be built, clinical studies have demonstrated good outcomes when ceramics are
Fig. 5 Radiological follow-up of a 63 year old male patient treated for degenerative spine disease. a Immediate post-operative; $\mathbf{b}, \mathbf{c}$ Bone substitute material still observed in the fusion mass two and three years after surgery
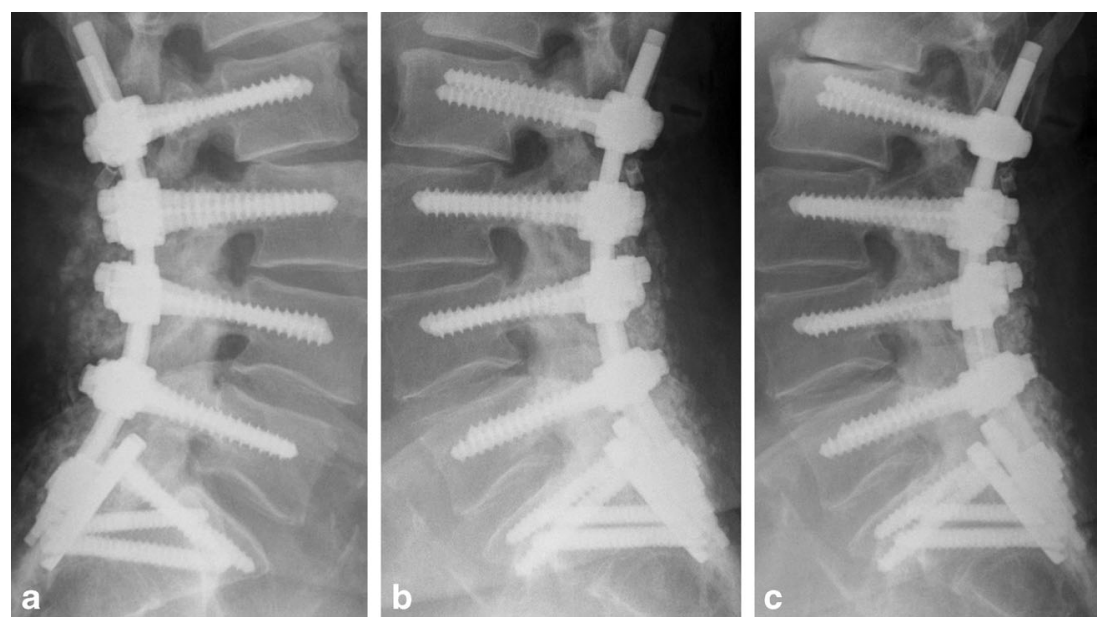
used as a bone graft extender with fusion rates of 82 to $90 \%$ in posterolateral fusions, whereas for multiple-level fusions, the fusion rates with calcium sulfate combined with laminectomy was also of $82 \%$ in the surgical management of scoliosis [8]. Nevertheless the rapid dissolution of calcium sulfate bone substitutes is not appropriate for spinal fusion indications where heterotopic bone has to develop to ensure a sustained mechanical support. However, several randomized studies established the potential of B-TCP biphasic materials to induce spinal fusion at the same rate as autologous bone $[13,18]$. The prospective randomized trial of 60 scoliotic patients treated with instrumented lumbar spinal fusion with either ICBG or coralline hydroxyapatite established a fusion rate of $100 \%$ in all groups at one year post-operatively [19]. Scaffolds made of mixtures of HA and B-TCP provide osteoconduction for bone production as well as long term stability leading to successful incorporation of a bone fusion mass. The stable HA portion of the graft resorbs over years, improving the structural rigidity of the fusion site while $\beta$-TCP resorbs within weeks or months [13]. This is also in agreement with a retrospective cohort analysis of three different bone grafts used in instrumented spinal fusion for adolescent idiopathic scoliosis, showing that outcomes are not influenced by the type of bone graft or substitute [20]. The overall fusion rate for all ceramic products reviewed recently as bone graft extender in the lumbar spine among 1332 patients was $86.4 \%$ and specific ceramic product did not significantly affect fusion rate, but ceramics used in combination with local autograft resulted in significantly higher fusion rates [21].

The results of the current study dealing with posterolateral fusion in different indications show that even in extensive fusion levels, excellent clinical, functional, and radiological outcomes can be achieved, without iliac crest graft when the appropriate therapeutic paradigm is used. Once the spinal segments to be fused are stabilized by internal fixation devices, the bone fusion can be achieved by the combination of a porous scaffold allowing cell and vessel ingrowth with local bone and bone marrow aspirate. The naturally-derived interconnected structure of Orthoss ${ }^{\circledR}$ allows ingrowth of bone cells and progenitor cells, together with endogenous factors enabling ectopic bone formation, in a posterolateral bone fusion mass. The use of Orthoss ${ }^{\mathbb{R}}$, as a highly porous and interconnected hydroxyapatite, with no organic residues that may induce local inflammation and inhibit bone ingrowth, in conjunction with bone marrow mesenchymal stem cells and local autologous bone offers an alternative to autologous bone graft using iliac crest. It is still considered that no bone substitute is better than fresh autogenous bone grafting with ceramics, in particular, being unable to fulfill all the roles of autologous bone graft [13]. However the combination used in this study, offers the advantage of suppressing the morbidity of iliac crest bone graft while providing, with minimal invasiveness, the biologic autologous material to enhance ectopic bone formation and fusion, as well as a relative long term stability of the HA scaffold. This has been achieved in the young scoliotic patients group as well as in elderly patients with degenerative vertebral lesions. Finally, the long duration of the resorption process of Orthoss ${ }^{\circledR}$ also contributes to a long term stability of the fusion, since it provides a continuous bone remodeling support within the fusion mass. In contrary, rapidly resorbable $\beta$-TCP, or even autografts are associated with initial decrease of the bone graft volumes. Up to $26 \%$ decrease in graft volume of autografts used in instrumented lumbar fusion has been reported in the first 12 post-op months [22]. Similar findings were reported by Kong et al. who showed that in instrumented posterolateral fusion, radio density and fusion rate changes, evoking an earlier resorption of local bone than a mixture of local bone and B-TCP [23].

Beyond successful fusion achieved by the combinations described here, local graft and Orthoss ${ }^{\circledR}$ and/or bone marrow aspirate, there is definitely an associated reduced operation time, an unlimited product availability even in extensive fusion levels, using a reliable methodology. Finally all morbidities associated with iliac crest graft can be reduced, providing a direct benefit for the patient.

The combination of graft materials used in our patients aided fusion by acting via several of four major mechanisms. Osteogenesis was promoted by local bone where grafts contained the cells that form bone or its precursors. Osteoinduction was stimulated through bone marrow aspirate and local bone with agents that recruit/differentiate cells to the fusion site, including non-bony sites. Osteoconduction was supported with the Orthoss ${ }^{\circledR}$ scaffold, and osteopromotion with agents provided by the marrow aspirate to enhance bone healing. Local bone combined with an osteoconductive and long term stable scaffold has been used in all cases reported in this study, where bone marrow aspirate was supplemented in $70 \%$ of these patients, thus enabling stable fusions at six months and functional recovery in three to six months, whichever indication is considered.

\section{Compliance with ethical standards}

Conflict of interest The authors declare that they have no conflict of interest. S. Boutrand was paid as a consultant by Geistlich Pharma AG for clinical data collection.

Ethical approval All procedures performed were in accordance with the ethical standards of the institutional research committee and with the 1964 Helsinki declaration and its later amendments.

For this type of study formal consent is not required.

Open Access This article is distributed under the terms of the Creative Commons Attribution 4.0 International License (http:// creativecommons.org/licenses/by/4.0/), which permits unrestricted use, distribution, and reproduction in any medium, provided you give appropriate credit to the original author(s) and the source, provide a link to the Creative Commons license, and indicate if changes were made. 


\section{References}

1. Reid JJ, Johnson JS, Wang JC (2011) Challenges to bone formation in spinal fusion. J Biomech 44(2):213-220. doi:10.1016/j. jbiomech.2010.10.021

2. Grabowski G, Cornett CA (2013) Bone graft and bone graft substitutes in spine surgery: current concepts and controversies. J Am Acad Orthop Surg 21(1):51-60. doi:10.5435/JAAOS-21-01-51

3. Sri D, Compson J (2014) Iliac crest bone grafting: raising awareness of a common pitfall. Int Orthop 38(8):1753. doi:10.1007/ s00264-014-2404-0

4. Hernigou P, Desroches A, Queinnec S, Flouzat Lachaniette $\mathrm{CH}$, Poignard A, Allain J, Chevallier N, Rouard H (2014) Morbidity of graft harvesting versus bone marrow aspiration in cell regenerative therapy. Int Orthop 38(9):1855-1860. doi:10.1007/s00264014-2318-x

5. Bereiter H, Melcher GA, Gautier E, Huggler AH (1991) Experience with Bio-Oss, a bovine apatite, in various clinical indications. Hefte Unfallheilkunde 216:117-126

6. Eismont FJ, Norton RP, Hirsch BP (2014) Surgical management of lumbar degenerative spondylolisthesis. J Am Acad Orthop Surg 22(4):203-213. doi:10.5435/JAAOS-22-04-203

7. Abdu WA, Lurie JD, Spratt KF, Tosteson AN, Zhao W, Tosteson TD, Herkowitz H, Longely M, Boden SD, Emery S, Weinstein JN (2009) Degenerative spondylolisthesis: does fusion method influence outcome? Four-year results of the spine patient outcomes research trial. Spine 34(21):2351-2360. doi:10.1097/BRS. 0b013e3181b8a829

8. Fischer CR, Ducoffe AR, Errico TJ (2014) Posterior lumbar fusion: choice of approach and adjunct techniques. J Am Acad Orthop Surg 22(8):503-511. doi:10.5435/JAAOS-22-08-503

9. Kho VK, Chen WC (2008) Posterolateral fusion using laminectomy bone chips in the treatment of lumbar spondylolisthesis. Int Orthop 32(1):115-119. doi:10.1007/ s00264-006-0274-9

10. Hsu WK, Nickoli MS, Wang JC, Lieberman JR, An HS, Yoon ST, Youssef JA, Brodke DS, McCullough CM (2012) Improving the clinical evidence of bone graft substitute technology in lumbar spine surgery. Global Spine J 2(4):239-248. doi:10.1055/s-00321315454

11. Dimar JR 2nd, Glassman SD, Burkus JK, Pryor PW, Hardacker JW, Carreon LY (2009) Two-year fusion and clinical outcomes in 224 patients treated with a single-level instrumented posterolateral fusion with iliac crest bone graft. Spine J: Off J North Am Spine Soc 9(11):880-885. doi:10.1016/j.spinee.2009.03.013

12. Sengupta DK, Truumees E, Patel CK, Kazmierczak C, Hughes B, Elders G, Herkowitz HN (2006) Outcome of local bone versus autogenous iliac crest bone graft in the instrumented posterolateral fusion of the lumbar spine. Spine 31(9):985-991. doi:10.1097/01. brs. $0000215048.51237 .3 \mathrm{c}$
13. Delecrin J, Takahashi S, Gouin F, Passuti N (2000) A synthetic porous ceramic as a bone graft substitute in the surgical management of scoliosis: a prospective, randomized study. Spine 25(5): $563-569$

14. Niu CC, Tsai TT, Fu TS, Lai PL, Chen LH, Chen WJ (2009) A comparison of posterolateral lumbar fusion comparing autograft, autogenous laminectomy bone with bone marrow aspirate, and calcium sulphate with bone marrow aspirate: a prospective randomized study. Spine 34(25):2715-2719. doi:10.1097/BRS. 0b013e3181b47232

15. Deyo RA, Ching A, Matsen L, Martin BI, Kreuter W, Jarvik JG, Angier H, Mirza SK (2012) Use of bone morphogenetic proteins in spinal fusion surgery for older adults with lumbar stenosis: trends, complications, repeat surgery, and charges. Spine 37(3):222-230. doi:10.1097/BRS.0b013e31821bfa3a

16. Deyo RA, Mirza SK, Martin BI, Kreuter W, Goodman DC, Jarvik JG (2010) Trends, major medical complications, and charges associated with surgery for lumbar spinal stenosis in older adults. JAMA 303(13):1259-1265. doi:10.1001/jama.2010.338

17. Kepler CK, Vaccaro AR, Hilibrand AS, Anderson DG, Rihn JA, Albert TJ, Radcliff KE (2014) National trends in the use of fusion techniques to treat degenerative spondylolisthesis. Spine 39(19): 1584-1589. doi:10.1097/BRS.0000000000000486

18. Dai LY, Jiang LS (2008) Single-level instrumented posterolateral fusion of lumbar spine with beta-tricalcium phosphate versus autograft: a prospective, randomized study with 3-year follow-up. Spine 33(12):1299-1304. doi:10.1097/BRS.0b013e3181732a8e

19. Korovessis P, Koureas G, Zacharatos S, Papazisis Z, Lambiris E (2005) Correlative radiological, self-assessment and clinical analysis of evolution in instrumented dorsal and lateral fusion for degenerative lumbar spine disease. Autograft versus coralline hydroxyapatite. Eur Spine J: Off Publ Eur Spine Soc, Eur Spinal Deformity Soc, Eur Section Cervical Spine Res Soc 14(7):630-638. doi:10. 1007/s00586-004-0855-5

20. Theologis AA, Tabaraee E, Lin T, Lubicky J, Diab M, Spinal Deformity Study G (2015) Type of bone graft or substitute does not affect outcome of spine fusion with instrumentation for adolescent idiopathic scoliosis. Spine 40(17):1345-1351. doi:10.1097/ BRS.0000000000001002

21. Nickoli MS, Hsu WK (2014) Ceramic-based bone grafts as a bone grafts extender for lumbar spine arthrodesis: a systematic review. Global Spine J 4(3):211-216. doi:10.1055/s-0034-1378141

22. Ha KY, Lee JS, Kim KW (2009) Bone graft volumetric changes and clinical outcomes after instrumented lumbar or lumbosacral fusion: a prospective cohort study with a five-year follow-up. Spine 34(16): 1663-1668. doi:10.1097/BRS.0b013e3181aacab5

23. Kong S, Park JH, Roh SW (2013) A prospective comparative study of radiological outcomes after instrumented posterolateral fusion mass using autologous local bone or a mixture of beta-tcp and autologous local bone in the same patient. Acta Neurochir 155(5): 765-770. doi:10.1007/s00701-013-1669-1 